\title{
Analysis of some quality indicators in cured Cola nitida (Vent)
}

\author{
Lowor, S. T, Aculey, P. C. and Assuah, M. K \\ Cocoa Research Institute of Ghana, P. O. Box 8, Tafo-Akim, Ghana
}

\begin{abstract}
Palatable and acceptable kola nuts for chewing are predominately obtained through curing. Curing involves the storage of fresh nuts in cane baskets lined with Musa sapientum (Linn) leaves or Mitragyna stipulosa (DC) leaves, with occasional turning and replacement of the leaves. The study explored how sensory attributes of kola nuts varied with curing duration (1 to 9 weeks) for phenolics and other biochemical compounds during the curing process of kola. The organoleptic assessment indicated that there are biochemical substances in the kola that influence the taste and the overall quality of the nuts. It was also clear that these biochemical substances are already present in the fresh nuts as precursors and are developed during the curing process. Total polyphenols could not be used wholly to account for astringency and bitterness in kola nuts. A subgroup, o-dihydric phenols could be better used to partly account for astringency and therefore as a marker.
\end{abstract}

Keywords: Phenolics; Cola nitida; Curing; Quality indicators; Organoleptic assessment

\section{INTRODUCTION}

Cola nitida (the kola nut) also known as cola, goro nut, cola seed and bissy is an important commercial and economic crop for many West African countries (Lovejoy, 1980) and Central Africa (Van Eijnatten, 1969). There are about twenty five species of the genus cola but only five or six species produce edible seeds commonly called 'nuts'. These are Cola nitida (vent), Cola acuminat Schott and Endl., Cola vertillata Thorn, C. anomala and C. ballay (Russell, 1955). However, only two species; $C$. nitida and acuminat are cultivated as plantation crops (Quarcoo, 1973; Daramola, 1978).

Kola, for many decades, has served and still serves as the main cash crop for many farmers in West Africa. Kola nut has been an important article of international trade in many parts of Africa (Nzekwu, 1961). Kola nuts are used as a masticatory and the only stimulant allowed to Muslims. For this reason there is a heavy trade of kola from the humid southern regions to the northern arid parts of West Africa. It is a very special and important item used in social and ceremonial activities by Africans, especially those of the Sahelian zones. Earlier on in the century, demand for kola nuts in the world markets for the manufacture of kola flavoured drinks, alcoholic beverages, candy and nutritional supplements (Beattie, 1970; Ogutuga, 1975) existed.

Kola nuts are extremely popular due to their high caffeine content. Kola nuts have a bitter taste and contain between $1-1.5 \%$ caffeine by weight (Clayton, 2002). They are also a source of antioxidants and contain small amounts of theobromine, d-catechin, Lepicatechin, kolatin, phlobaphens, antioxidant pigment, betaine and protein. Kola extract is popular ingredient in fat loss supplements. It suppresses hunger, aids digestion of food and acts as a diuretic.

Fresh kola nuts are highly hydrated, have very bright colours and are astringently bitter. They contain a wide array of complex secondary plant metabolites and polyphenolics known to be mainly responsible for the astringency and bitter taste in the fruits. Several curing and preservation methods have been tried to remove the astringency, bitterness and high moisture content to make the nuts palatable and acceptable (Osei Bonsu et al., 1977; Takrama et al., 2000). Curing usually involves the storage of the fresh cola nuts for months or years in cane baskets properly lined with either banana or Mitragygna stipulosa

During curing, polyphenols are subjected to biochemical modifications through polymerization and complexing to proteins and hence decreasing solubility and astringency (Bonhevi and Coli, 1997). The amount of polyphenols is also substantially reduced by enzymatic browning caused by polyphenol oxidase (PPO) (Wollgast and Anklam, 2000). High levels of polyphenol oxidase responsible for enzymatic browning have also been reported in $C$. nitida (Prohp et al., 2009).

Cured kola nuts that are not slimy, not astringently bitter in taste but palatable and crispy are normally considered to have the desirable characteristics of good quality (Quarcoo, 1973). The most important factors that determine the value of kola nuts at the 
local markets are size, flavour, colour and keeping qualities of the nuts (Quarcoo, 1973). While size and colour can be physically determined, flavour and keeping quality are ultimately determined by the method of curing and preservation. Most often, taste panels, using the human sensory mechanism in organoleptic test, are used to determine the flavour and quality of the product. Organoleptic method of determining flavour in kola is a subjective approach that has not been standardised.

The high demand for kola nuts in the domestic and international markets for use in the food and pharmaceutical industries necessitates an accurate and efficient chemical and biochemical analytical methods which can characterize and quantify the native constituents in fresh and cured kola nuts for quality determination.

Consumer consciousness and demand for higher degree of quality and safety in food and health care products has increased over the years. This has called for equally higher quality standards for product ingredients. The biochemical modifications, especially the changes in polyphenols and phenolic acids during the curing of kola nuts have not been well studied and exploited in assessing kola quality.

In this study, we report on how sensory attributes of kola nuts vary with curing for certain phenolic and biochemical compounds present in the nuts with the view to understanding the curing/fermentation process of kola.

\section{MATERIALS AND METHODS}

Plant material, curing process, phenolic analysis and organoleptic assessment: The experiment was carried out at the Cocoa Research Institute of Ghana, Tafo.

Pods for the experiment were obtained from the Cocoa Research Institute of Ghana (CRIG) kola plots during the 2007/08 kola season. Cola nitida nuts contained in pods were separated into Red, Pink and White and cured separately according to their colours. The curing procedure carried out was the traditional method as described by Osei-Bonsu et al. (1977). Briefly, 400 nuts of each colour were packed into cane baskets lined with banana leaves. The nuts were covered with the same leaves and stored at room temperature. 4 replicates of each colour were used. 30 fresh nuts from the three colours were sampled for moisture content, dry weight, carbohydrates and total polyphenol content. Quantitative analysis of the phenolic compounds and carbohydrates in the fresh nuts was carried out to determine their initial levels. Thereafter, batch samples were taken weekly for organoleptic and chemical analysis. Changes in the values of these compounds were monitored weekly for 9 weeks. Organoleptic assay was carried out by a panel of ten experienced kola nut chewers from the Cocoa Research Institute of Ghana using a scale of $1-10$. Bigger scores represented greater intensity of the parameter being measured. Descriptors of the sensory attributes used by the taste panel were: astringency, appearance, aroma, texture and bitterness.

The total phenolic content was analysed using FolinCiocalteu reagent following a modified procedure of Singleton and Rossi (1965). One $\mathrm{mL}$ of the appropriately diluted sample was mixed with $5 \mathrm{~mL}$ of Folin-Ciocalteu reagent $(1: 10, v / v$, diluted with distilled water). The reaction was neutralised by adding $4 \mathrm{~mL}$ of $75 \mathrm{~g} \mathrm{~L}^{-1}$ sodium carbonate. Samples were held for 2 hours at $25 \pm 2^{\circ} \mathrm{C}$ and the absorbance of the resulting blue color was measured at $760 \mathrm{~nm}$ against a reagent blank on a Cecil CE 7400 UV-visible spectrophotometer (Cecil Instruments, Cambridge, England).

The total phenolic content was determined from a catechin calibration curve prepared and analyzed concurrently with the samples. Samples were analyzed in four replicates. O-dihydric phenols and Flavanols were assayed following the method of Johnson and Schaal (1957) and Swain and Goldstein (1964) respectively.

Carbohydrate analysis: Free sugars were extracted for analysis with boiling $80 \%$ ethanol. Starch was determined as glucose in acid extracts of the alcohol extracted samples (Adomako, 1972). Total carbohydrate was determined by the Dubois (1956) method using phenol-sulphuric acid reagent (Gomez et al., 2002).

Statistical analysis: The experiment had a completely randomised design. Data from four replicates of all treatments were subjected to analysis of variance using Genstat 9. Fisher's least significant difference (LSD) method was used to determine confidence intervals for all pair wise differences between means. Significance was accepted at the $P$ $<0.05$ level.

\section{RESULTS AND DISCUSSION}

Moisture, phenolics and carbohydrates: The moisture content of nuts cured for nine weeks was 
$44.16 \pm 0.5 \%$ for red nuts, $42.49 \pm 1.3$ for white nuts and $42.76 \pm 1.0$ for pink nuts (Figure 1). The initial moisture content of the nuts ranged between $52.45 \pm$ 1.2 for red, $56.84 \pm 0.5$ for white and $54.35 \pm 0.3$ for pink. The white nuts initially had significantly higher moisture content then the red and pink. Gradual loss of moisture from the nuts during curing indicated the curing process was properly controlled and good. Quick loss of moisture results in wrinkled, unacceptable and dried nuts that are not marketable. The initial moisture loss during the first half of the curing was higher than the second. At the end of the curing, however, there was no significant $(P>0.05)$ difference in the moisture content of the cured nuts.

The O-dihydric phenols during curing in the variously coloured nuts ranged between 1.51 and $11.60 \mathrm{mg} \mathrm{g}^{-1}$ fresh weight (Table 1). The analysis showed significant differences between the initial levels of the o-dihydric phenols in the variously coloured nuts, with the red having the highest $\left(9.18 \mathrm{mg} \mathrm{g}^{-1}\right)$ and pink $\left(1.51 \mathrm{mg} \mathrm{g}^{-1}\right)$ the lowest. In all three coloured nuts, Odihydric phenols increased with curing duration to a maximum in the fifth week before dropping in the following weeks. Both colour and curing duration significantly influenced the level of O-dihydric phenols. Generally, the trend observed followed that of the total polyphenols (Fig. 2). In times of glut, nuts are cured for much longer periods (6months - 1 year). It is extrapolated from the results obtained that the downward trend of the o-dihydric phenols would continue till a minimum is reached.

Significant interaction of colour and curing was observed on the total polyphenols present in the kola nuts (Fig 2). Polyphenols in plant foods are greatly influenced by genetic factors, variety, degree of ripeness and environmental conditions (Bravo, 1998; Robards \& Antolovich 1997). In this study, colour and curing duration had a significant effect $(p \leq 0.05)$ on the level of polyphenolics. Significant differences existed in the initial polyphenolic content of the nuts, with the red having the highest concentration (48.87 $\left.\mathrm{mg} \mathrm{g}^{-1}\right)$, followed by the white $\left(17.29 \mathrm{mg} \mathrm{g}^{-1}\right)$ and the pink $\left(8.50 \mathrm{mg} \mathrm{g}^{-1}\right)$. Mean concentration of polyphenolics over the nine weeks was $43.04,33.85$ and $32.52 \mathrm{mg} \mathrm{g}^{-1}$ for red, pink and white respectively. Prohp et al., (2009) reported a similar trend for fresh Nigerian C. nitida nuts, where the red nuts $(33.50 \mathrm{mg}$ $\left.\mathrm{g}^{-1}\right)$ had higher levels of polyphenolics than the white $\left(29.50 \mathrm{mg} \mathrm{g}^{-1}\right)$. Odebode, (1996) reported variation of total phenols between differently coloured nuts within species with the red having more (about three times) than pink and pink more than white in C. nitida.
Curing affected the level of polyphenolics in the nuts. Generally, the amount of polyphenolics increased from week zero during curing to a maximum in weeks three, five and seven for pink, red and white respectively. Differences between the colours narrowed at the $9^{\text {th }}$ week with polyphenol levels of $41.26,34.72$ and $30.85 \mathrm{mg} \mathrm{g}^{-1}$ recorded for white, red and pink respectively.

Within the cola family, $C$. nitida has been reported to be more astringent than Cola acuminata because of the usually high polyphenols in the former (Odebode, 1996). The result does not confirm general beliefs that like cocoa, curing in kola results in the reduction of polyphenols in nuts, reducing the astringency and improving palatability. Unlike cocoa where the heap during fermentation contains a lot of microbes, high sugars and proteins in the pulp, reduction and conversion of phenolics through condensation reaction is less likely to be the case. Phenolic activities are likely to be affected by the high level of polyphenol oxidase reported to be present in the nuts (Prohp, 2009), accounting for the generally high incidence of enzymatic browning in kola nuts. Results therefore seem to suggest that quantification of total polyphenols can therefore not be used as a marker for degree of curing in kola.

Catechin and epicatechin have been identified as the flavonoids present in $C$. nitidia, with catechin being the most dominant (Niemenaka, 2008). The initial levels of the flavonoid compounds varied within the differently coloured species with red having the highest (figure 3 ). This confirms earlier findings that flavonoid composition varies greatly in different fruit species (Robards \& Antolovich 1997; Macheix et al. 1990). The overall metabolic activities in these compounds were very minimal compared to those detected in the carbohydrates and the total polyphenols. Fruit qualities in terms of colour, flavour, bitterness and texture and undesirable brown pigmentation in fruits following bruising or cutting and/ or storage have sometimes been attributed to contributions from flavonoid (Amiot et al. 1997, Robards \& Antolovich 1997). The final level of the flavonoids was higher than the initial indicating that the curing process affected the level of flavonoid.

Relative amounts of soluble sugars present in the nuts during curing are presented in Table 2. Colour and curing duration significantly influenced the soluble sugars present in the nuts at each stage. The initial sugar concentrations of $8.77,7.90$ and $5.36 \mathrm{mg}$ $\mathrm{g}^{-1}$ fresh weight for white, pink and red nuts respectively seems to indicate that white nuts of $C$. 
nitida contained relatively higher soluble sugars compared to the red and pink. No general trend, however, was established during the course of the curing. Nuts being active and respiring during curing generally utilize sugars and hence could account for the fluctuating and varying levels of the soluble sugars during the curing process.

Organoleptic test: Evaluation of cured C. nitida using a 10 point scale, showed that the greatest effect of the curing was on taste, followed by aroma and texture. This distinguishes cured nuts from uncured nuts. In addition, the results indicate that the characteristic of fresh kola nuts such as red was also preferred by the panelist.

Appearance (colour): Both curing duration and colour significantly $(P<0.05)$ affected the perception on appearance of nuts (Table 3 ). Fresh nuts had bright colours, becoming dull as the curing progressed. The ox-blood red colour for the fresh red nuts changed into dull red to reddish brown on curing. The bright white cream colour of the white nut converted to light yellow cream to dark cream colour and the bright pink colour also changed to dull pink or whitish pink colour upon curing. The colour changes could be attributed to slight tanning as a result of polyphenol oxidase activity (Forsyth and Romboust, 1951). The colour changes also made the cured nuts less attractive compared to the fresh nuts. In terms of appearance, all the three coloured nuts were preferred fresh compared to the cured.

Bitterness and Astringency: All the fresh coloured nuts were found to be very bitter with the red nuts rating highest followed by the pink and then the white (Table 4). The bitterness decreased as curing progressed (Table 5). Bitterness and astringency were positively correlated (Figure 4). In cocoa, astringency has been attributed to the tanning effect of mono- and oligomeric polyhydroxyphenols, mainly flavonoids, leucocyanidins, catechins and anthocyanidins, which are stored in vacuoles of specialized cells of the seed cotyledons (Kim and
Keeney, 1984; Robinson et al. 1961; Goldstein and Swain, 1963). These compounds are somewhat modified during fermentation in the presence of oxygen: hydrolysis of anthocyanins (to anthocyanidins, galactose and arabinose), dimerisation of leucocyanidins (acid catalysis), exudation of flavonoids from seeds and subsequently reduced during drying by enzymatic browning (Kim and Keeney, 1984; Robinson et al. 1961; Goldstein and Swain, 1963). These processes even though might occur in the kola during curing, would be to a limited extent and hence the small level of tanning and changes in the polyphenol content. Results of the study showed that generally the total polyphenol levels increased compared to the initial and could not account for the reduction of the astringency (Table 6) that has been attributed to polyphenols in the nuts (Odebode, 1996). Red nuts were more astringent than white (Table 7). Total polyphenol levels could therefore not be used to determine the astringent level in kola nuts. Biochemical reactions within the nuts, however, could be involved in the conversion of one form of polyphenol to another with much less bitter and astringency characteristics. The o-dihydric phenol levels in the nuts kept on decreasing with time and could be the determining phenol factor in astringency and bitterness reduction (Table 1).

Texture: Curing significantly $(P<0.05)$ influenced texture of nuts (Table 8). Fresh nuts were highly hydrated, pliable and difficult to break but they became dehydrated, easy to break and crispy on curing and hence texture improved. Scores for texture did not significantly $(P>0.05)$ vary among the variously coloured nuts (Table 9 ).

Aroma (Flavour): The cured nuts were more flavoured and preferred to the fresh nuts (Table 10). This supported earlier work by Lowor (2008) who reported the development of volatile aroma compounds in cured nuts compared to sun dried and fresh nuts. In terms of aroma, however, colour did not seem to influence preference of tasters (Table 11). 
Agric. Biol. J. N. Am., 2010, 1(6): 1206-1214

Table 1: Variation in O-dihydric phenol $\left(\mathrm{mg} \mathrm{g}^{-1}\right)$ of white, red and pink kola nuts during curing

\begin{tabular}{|c|c|c|c|c|}
\hline \multirow[b]{2}{*}{ Curing duration (weeks) } & \multicolumn{3}{|c|}{$\begin{array}{l}\text { O-dihydric phenols }\left(\mathrm{mg} \mathrm{g}^{-1}\right) \text { in nuts of } \\
\text { various colours }\end{array}$} & \multirow[b]{2}{*}{ Mean } \\
\hline & Pink & Red & White & \\
\hline 0 & 1.51 & 9.18 & 3.39 & 4.69 \\
\hline 1 & 3.36 & 5.74 & 3.09 & 4.06 \\
\hline 2 & 3.56 & 3.03 & 3.49 & 3.36 \\
\hline 3 & 9.01 & 4.50 & 2.58 & 5.37 \\
\hline 4 & 9.09 & 7.11 & 8.15 & 8.12 \\
\hline 5 & 10.99 & 11.60 & 9.65 & 10.75 \\
\hline 6 & 6.97 & 8.15 & 6.83 & 7.32 \\
\hline 7 & 9.17 & 7.60 & 9.72 & 8.83 \\
\hline 8 & 6.84 & 8.35 & 6.77 & 7.32 \\
\hline 9 & 6.65 & 6.15 & 7.51 & 6.77 \\
\hline Means & 6.72 & 7.14 & 6.12 & 6.66 \\
\hline LSD colour $(P=0.05)$ & 0.43 & & & \\
\hline LSD duration $(P=0.05)$ & 0.39 & & & \\
\hline LSDinteraction $(P=0.05)$ & 0.68 & & & \\
\hline
\end{tabular}

Table 2: Variation in total soluble sugars $\left(\mathrm{mg} \mathrm{g}^{-1}\right)$ of white, red and pink kola nuts during curing

\begin{tabular}{|c|c|c|c|c|}
\hline \multirow[b]{2}{*}{ Curing duration (weeks) } & \multicolumn{3}{|c|}{$\begin{array}{l}\text { soluble sugar concentration }\left(\mathrm{mg} \mathrm{g}^{-1}\right) \text { in nuts of various } \\
\text { colours }\end{array}$} & \multirow[b]{2}{*}{ Mean } \\
\hline & Pink & Red & White & \\
\hline 0 & 7.90 & 5.36 & 8.77 & 7.34 \\
\hline 1 & 7.28 & 13.73 & 15.15 & 12.05 \\
\hline 2 & 7.04 & 8.23 & 5.66 & 6.98 \\
\hline 3 & 7.31 & 4.62 & 9.46 & 7.13 \\
\hline 4 & 4.64 & 3.27 & 4.68 & 4.20 \\
\hline 5 & 6.89 & 4.27 & 5.58 & 5.58 \\
\hline 6 & 10.94 & 9.74 & 7.15 & 9.27 \\
\hline 7 & 8.79 & 7.08 & 9.43 & 8.43 \\
\hline 8 & 7.07 & 7.75 & 10.23 & 8.35 \\
\hline 9 & 15.69 & 6.81 & 5.56 & 9.35 \\
\hline Means & 8.35 & 7.09 & 8.17 & 7.87 \\
\hline LSD colour $(\mathrm{P}=0.05)$ & 0.81 & & & \\
\hline LSD duration $(P=0.05)$ & 1.48 & & & \\
\hline LSDinteraction $(P=0.05)$ & 2.55 & & & \\
\hline
\end{tabular}

Table 3: Scores for Appearance of nuts during curing

\begin{tabular}{|c|c|c|c|c|c|c|c|c|c|c|}
\hline \multirow[t]{2}{*}{ Nut colour } & \multicolumn{10}{|c|}{ Curing duration/weeks } \\
\hline & 0 & 1 & 2 & 3 & 4 & 5 & 6 & 7 & 8 & 9 \\
\hline Pink & 5.5 & 6.3 & 5.3 & 5.0 & 5.5 & 5.3 & 5.4 & 5.3 & 6.3 & 5.7 \\
\hline Red & 6.7 & 6.0 & 6.5 & 5.5 & 6.0 & 6.8 & 6.2 & 5.3 & 6.2 & 6.1 \\
\hline White & 6.5 & 6.0 & 5.7 & 5.7 & 5.4 & 5.5 & 6.1 & 7.0 & 5.8 & 5.8 \\
\hline LSD colour $(\mathrm{P}=0.05)$ & 0.3 & & & & & & & & & \\
\hline LSD Interaction $(P=0.05)$ & 0.9 & & & & & & & & & \\
\hline
\end{tabular}




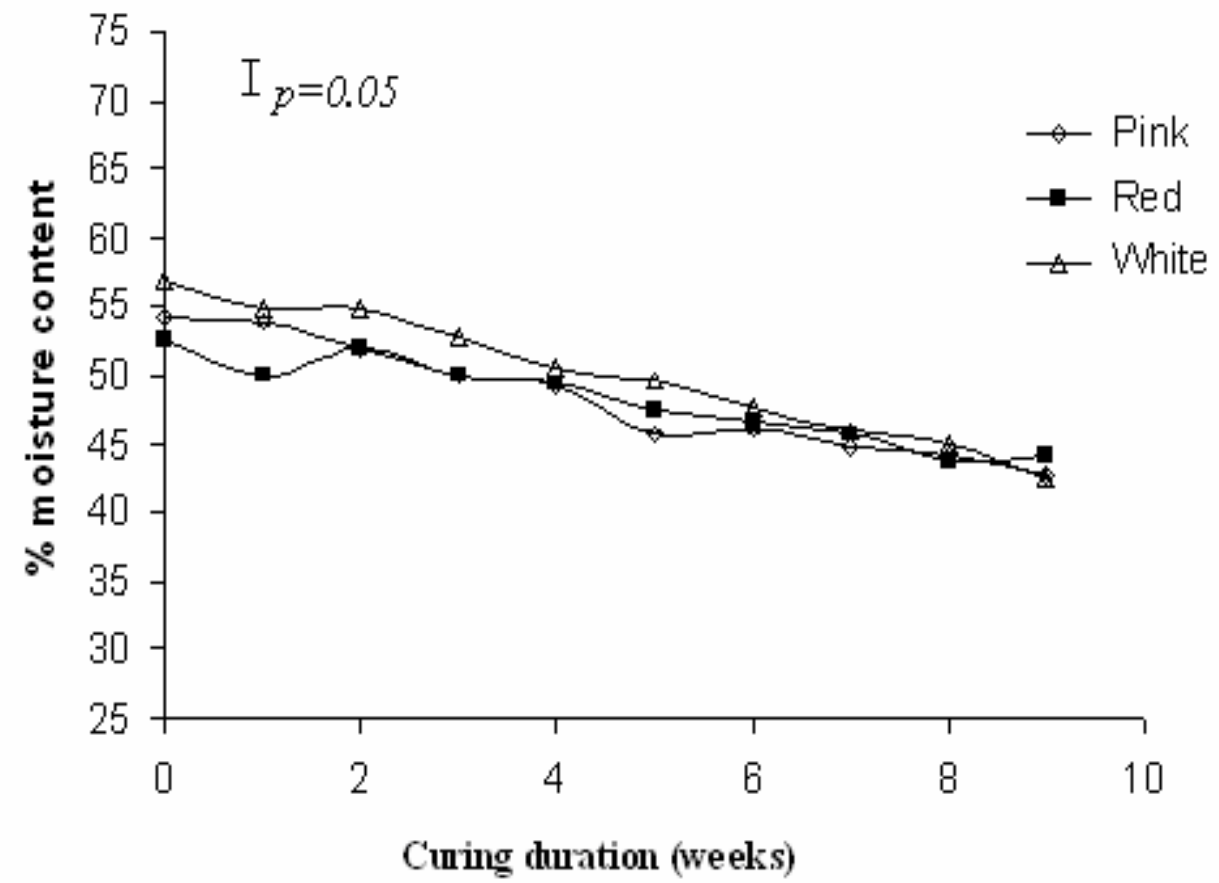

Fig 1: Variation in moisture content of kola nut of various colours during curing

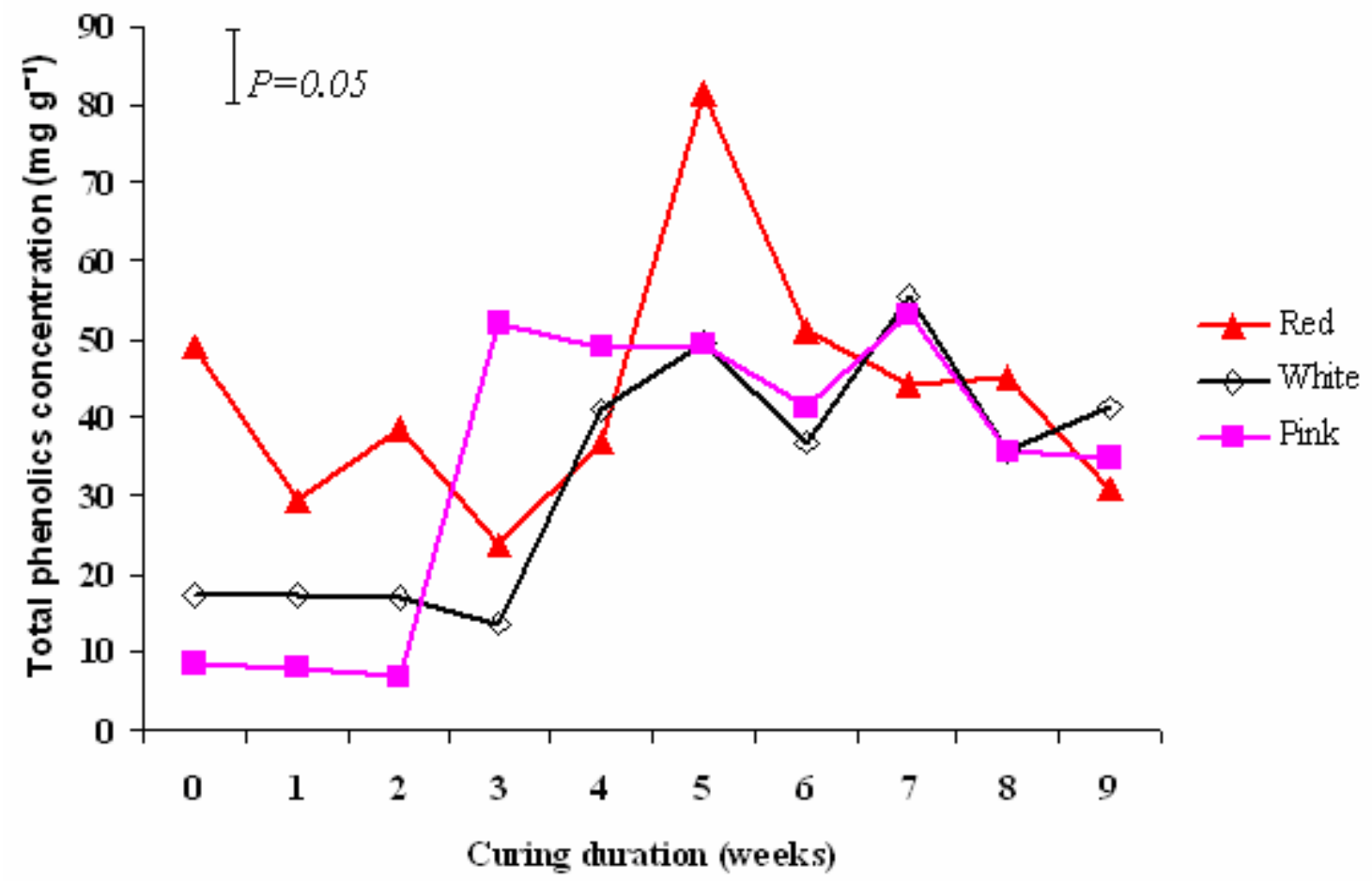

Fig 2: Variation in total phenolics ( $\mathrm{mg} \mathrm{g}^{-1}$ ) of white, red and pink kola nuts under curing 


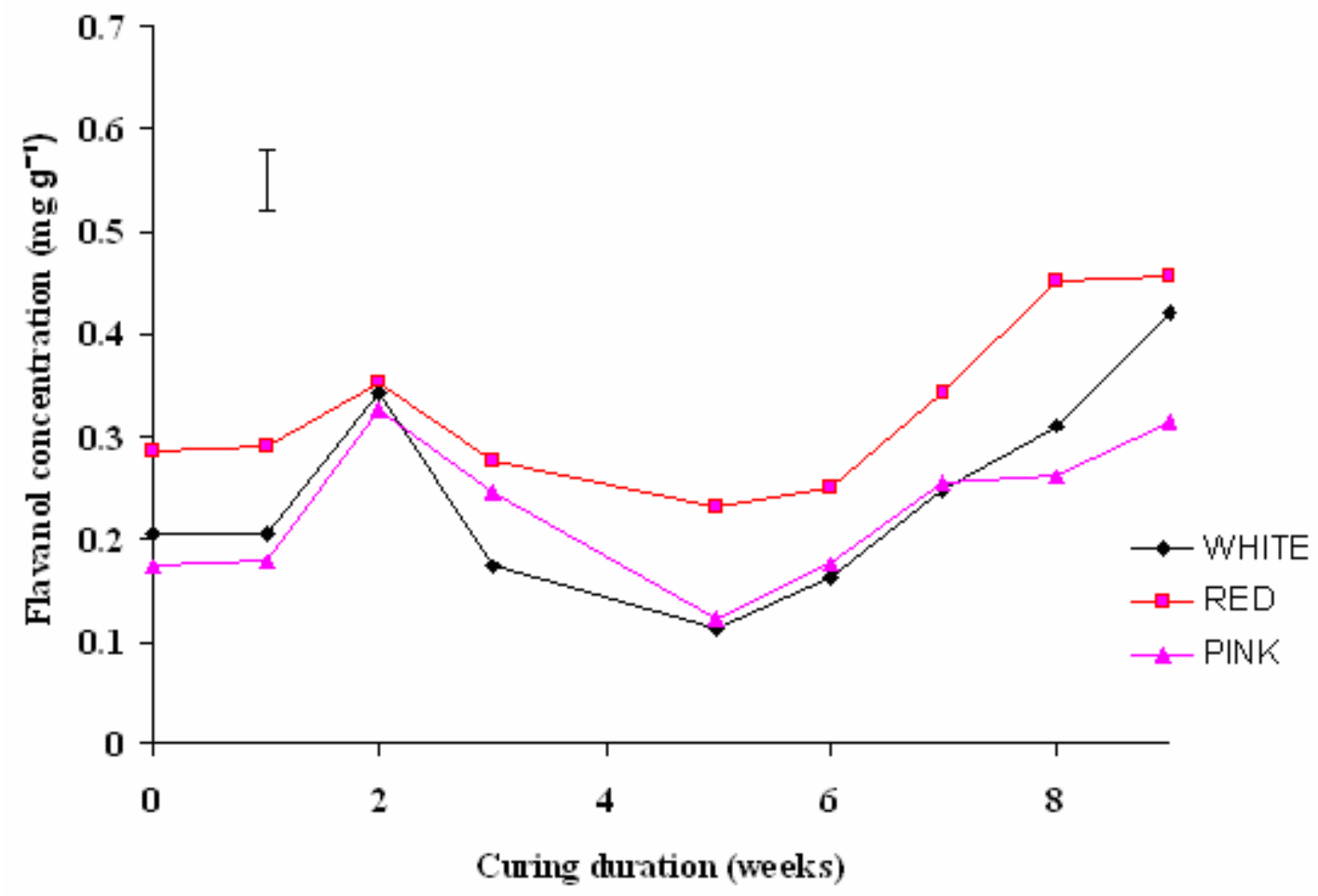

Fig 3: Variation in total flavanols $\left(\mathrm{mg} \mathrm{g}^{-1}\right)$ of white, red and pink kola nuts under curing

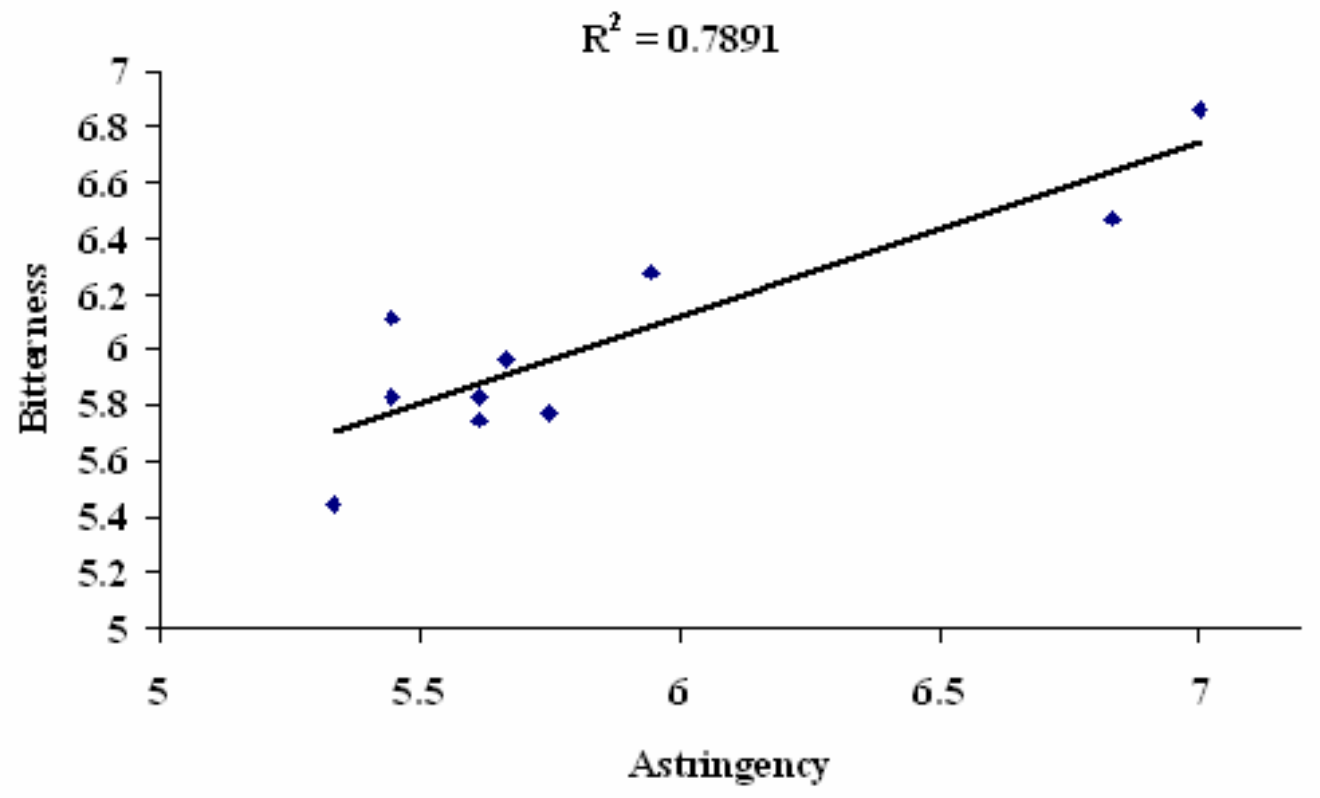

Fig 4: Correlation between Bitterness and astringency in $C$. nitida nuts during curing. 
Agric. Biol. J. N. Am., 2010, 1(6): 1206-1214

Table 4: Mean bitterness score for colour

\begin{tabular}{|c|c|c|c|c|c|c|c|c|c|c|}
\hline Colour & & $\operatorname{Re}$ & & & Pink & & & White & & \\
\hline Mean score & & 6.5 & & & 5.9 & & & 6.1 & & \\
\hline Curing duration (weeks) & 0 & 1 & 2 & 3 & 4 & 5 & 6 & 7 & 8 & 9 \\
\hline Mean score & 8.1 & 7.4 & 6.0 & 5.9 & 5.8 & 5.8 & 5.7 & 5.3 & 5.5 & 4.9 \\
\hline LSD (P= 0.05) & 0.4 & & & & & & & & & \\
\hline Curing duration (weeks) & 0 & 1 & 2 & 3 & 4 & 5 & 6 & 7 & 8 & 9 \\
\hline Mean score & 7.0 & 6.8 & 5.9 & 5.7 & 5.4 & 5.6 & 5.6 & 5.8 & 5.3 & 5.4 \\
\hline LSD $(P=0.05)$ & 0.7 & & & & & & & & & \\
\hline
\end{tabular}

Table 7: Mean astringency score for colour

\begin{tabular}{llll}
\hline Colour & Red & Pink & White \\
\hline Mean score & 6.0 & 5.9 & 5.7 \\
\hline
\end{tabular}

Table 8: Mean texture score for curing duration

\begin{tabular}{lllllllllll}
\hline Curing duration (weeks) & 0 & 1 & 2 & 3 & 4 & 5 & 6 & 7 & 8 & 9 \\
Mean score & 5.1 & 5.6 & 5.3 & 5.4 & 5.6 & 4.9 & 5.8 & 6.2 & 6.4 & 6.8 \\
\hline LSD $(\mathrm{P}=0.05)$ & 0.7 & & & & & & & & &
\end{tabular}

Table 9: Mean texture score for colour

\begin{tabular}{llll}
\hline Colour & Red & Pink & White \\
\hline Mean score & 5.6 & 5.7 & 5.8 \\
\hline
\end{tabular}

Table 10: Mean aroma score for curing duration

\begin{tabular}{lllllllllll}
\hline Curing duration (weeks) & 0 & 1 & 2 & 3 & 4 & 5 & 6 & 7 & 8 & 9 \\
Mean score & 4.9 & 5.3 & 5.4 & 5.2 & 5.5 & 5.4 & 5.7 & 6.5 & 6.8 & 6.9 \\
\hline LSD (P=0.05) & 0.4 & & & & & & & &
\end{tabular}

LSD (P= 0.05)

0.4

Table 11: Mean aroma score for colour

\begin{tabular}{llll}
\hline Colour & Red & Pink & White \\
\hline Mean score & 5.8 & 5.7 & 5.8
\end{tabular}

\section{CONCLUSION}

Total polyphenols could not be used wholly to account for astringency and bitterness in kola nuts. A subgroup, o-dihydric phenols could be better used to partly account for astringency. The organoleptic assessment gives the indication that there are chemical and biochemical substances in the kola that influence the taste and the overall quality of the nuts. It is also clear that these chemical and biochemical substances are already present in the fresh nuts as precursors and are developed during the curing process.

\section{ACKNOWLEDGEMENTS}

This paper No. (CRIG/11/2009/012/002) is published with the kind permission of the Executive Director of the Cocoa Research Institute of Ghana. We acknowledge the assistance of laboratory technicians of the Physiology/Biochemistry in the analysis. 


\section{REFERENCES}

Adomako, D. (1972). Studies on mealybug (Planococcoides njalensis) nutrition: a comparative analysis for the free carbohydrate and nitrogenous compounds in cocoa bark and mealy bug honeydew. Bulletin of Entomological Research 61, 523-531.

Amiot, M.J., Fleuriet, A., Cheynier, V. and Nicolas, J. (1997). Phenolic compounds and oxidative mechanism in fruits and vegetables. In: Francisco A. Tomás-Barberán, Richard J. Robins (eds) Phytochemistry of Fruits and Vegetables. Oxford University Press, New York, p 51-85.

Beattie, G.B. (1970). Soft drink flavours: Their history and characteristics. 1: Cola for kola flavours. The Flavour Industry. pp. $390-394$.

Bonhevi, J.S. and Coli, F.V. (1997). Evaluation of purine alkaloids and diketopiperazines content in processed cocoa powder. Food Chemistry 60, 356-370.

Bravo, L. (1998). Polyphenols: chemistry, dietary sources, metabolism and nutritional significance. Nutrition Reviews 56 (11), 317-333.

Clayton, S. (2002). Herbal Ephedric/caffeine for weight loss: a 6-month Randomized safety and efficacy trial. International Journal of Obesity and Related Metabolic Disorders 26 (5), 593-604.

Daramola, A.M. (1978). Insect pest of kola in Nigeria. Research Bulletin No. 3, Cocoa Research Institute of Nigeria, Ibadan 33pp.

Dubois, K.A., Gilles, J.K., Hamilton, P.A. Rebers and Smith, F. (1965). Colorimetric Method for Determination of sugars and related substances. Analytical Chemistry 28, 350.

Forsyth, W.G.C. and Romboust, J.E. (1951). Our approach to the study of cocoa fermentation. Report of. Cocoa Conference, London., 73-81.

Goldstein, J. and Swain, T. (1963). Changes in tannins in riping fruits. Phytochemistry 2 (4), $371-383$.

Gomez, L. Rubio, E. and Augi, M. (2002). A new procedure for extraction and measurement of soluble sugars in ligneous plants. Journal of the Science of Food and Agriculture 82, 360-369.

Johnson, G. and Schaal, L.A. (1957). Chlorogenic acid and ortho-dihyroxy phenols in scab resistant Russet burbank and scab susceptible triumph potato tubers of different maturities. Phytopathology 47, 253-258.

Kim, H. and Keeney, P.G (1984). (-)-epicatechin content in fermented and unfermented cocoa beans. Journal of Food Science 49, 1090-1092.

Lowor, S.T. (2008). Studies on the chemical composition and storage parameters of sun-dried Kola nuts. African Journal of Agricultural Research 3 (2), 130-133.

Lovejoy P.E. (1980). Kola in the History of West Africa (La kola dans I'histoire de l'Afrique occidentale) Cahiers d'Études Africaines, Vol. 20, Cahier 77/78, pp. 97-134.

Macheix, J.J, Fleuriet, A. and Billot, J. (1990). Fruit Phenolics. Boca Raton, FL, CRC Press.
Niemenaka, N., Onomoa, P.E., Fotsoa, Liebereib, R., Ndoumoua, D.O. (2008). Purine alkaloids and phenolic compounds in three Cola species and Garcinia kola grown in Cameroon. South African Journal of Botany 74 (4), 629-638.

Nzekwu, O. (1961). Kola nut. Nigeria Magazine 71, 298 - 305

Odebode, A. C. (1996). Phenolic compounds in the kola nut (Cola nitida and Cola acuminata) (Sterculiaceae) in Africa. Revista de Biologia Tropical, 44, 513-515.

Ogutuga, D.B.A. (1975). Chemical composition and potential commercial uses of kola nuts Cola nitida (Vent.) Schott \& Endlicher. Ghana Journal of Agricultural Science 8, 121 125.

Osei-Bonsu, K., Bonaparte, E. E. N. A. and Afrifa, M. K. (1977). Cola storage experiments. Report of the Cocoa Research. Institute of Ghana, 1974/75. pp. $47-53$.

Prohp, T.P., Ekpo, K.E. Osagie, E.V, Osagie, A., Obi, H. (2009). Polyphenol contents and polyphenol oxidase activities of some Nigerian Kolanuts. Pakistan Journal of Nutrition 8 (7), 1030-1031.

Quarcoo, T. (1973). A Handbook on Kola, Cocoa Research Institute of Nigeria, Ibadan. 90pp.

Robards K. and Antolovich, M. (1997). Analytical chemistry of fruit bioflavonoids. Analyst 122, 11R-34R.

Robinson, T., Ranalli, A. and Phillips, A.W. (1961). Changes in cocoa tannins during processing. Journal of Agriculture and Food Chemistry 9, 295-298.

Roelofsen, P.A. (1958). Fermentation, drying, and storage of cacao beans. Advances in Food Research 8, 225-296

Russell, T.A. (1955). The kola of Nigeria and Cameroon. Tropical Agriculture Trinidad. 32(3), 210.

Singleton, V.L. and Rossi, J.A. (1965). Colorimetry of total phenolics with phosphomolybdic phosphotungstic acid "reagents". American Journal of Enology and Viticulture 16(3), 144-158.

Swain, T. and Goldstein, J.L. (1964). In: Methods in Polyphenol Chemistry (Peisham, J. B. ed). Pergamon Press Oxford, $131-146$.

Takrama, J.F., Sarfo, J.E., Aculey, P.C., Osei-Bonsu, K., Kojo Montford and Nketsia-Tabiri, J. (2000). The use of gamma radiation for the preservation of kola nuts. Journal of the Ghana Science Association 2 (3), 2000, 184-192.

Van Eijnatten, C.L.M. (1969). Kola: Its botany and Cultivation. Communication no. 59 of the Department of Agricultural Research, Koninklijk Instituut voor de tropen, Amsterdam.

Wollgast, J. and Anklam, E. (2000). Polyphenols in Theobroma Cacao changes in composition during the manufacture of chocolate and methodology for identification and quantification. Food Research International 33 (6), 423 447. 